\title{
Farklı post boylarının ve farklı siman kullanımının kron ile restore edilmiş dişlerin kırılma dayanımına etkisi ${ }^{*}$
}

\author{
Halil ibrahim Kılınç ${ }^{1}$, Tuğrul Aslan², Kerem Kılıç ${ }^{1}$ Özgür Er ${ }^{3}$
}

Selcuk Dent J, 2016; 3: 20-26

Bašuru Tarihi: 29 Ekim 2015 Yayına Kabul Tarihi: 08 Nisan 2016

\begin{abstract}
Öz
Farklı post boylarının ve farklı siman kullanımının kron ile restore edilmiş dişlerin kırılma dayanımına etkisi
\end{abstract}

Amaç: Bu çalışmanın amacı post-kor ve kronla restore edilmiş dişlerde farklı simantasyon materyallerinin ve post uzunluklarının kırılma direncine etkisini değerlendirmektir.

Gereç ve Yöntemler: Benzer boylara sahip 40 mandibular premolar dişin kronları uzaklaştırıldı. Kanal tedavileri yapıldıktan sonra dişler akrilik bloklara gömüldü. Örnekler ilk olarak ikiye ayrıldı. $10 \mathrm{~mm}$ ve $5 \mathrm{~mm}$ derinliklerinde sirküler post boşlukları, sırasıyla \#0.5 ve \#2 kodlu üretici frezleri ile hazırlandı. Post (D.T. Light-Post) simantasyonu aşamasında, her post grubundaki 10 örnek kendinden adezivli rezin siman (Rely $\mathrm{X}$ ) ile simante edildi. Diğer 10 örnek kendinden asitli kompozit siman (Clearfill Esthetic Cement) ile simante edildi $(n=10)$. Tüm örnekler kompozit korlar ile restore edildi ve toplamda yaklassık $5^{\circ}$ lik konverjans açısıyla 6 $\mathrm{mm}$ boyunda (1 $\mathrm{mm}$ ferrule dahil) prepare edildi. Sonra, tüm disler tam metal kronlarla, cam iyonomer simanla simante edilerek restore edildi. Termal döngü ile yorma sonrası, tüm örneklere kırıma dayanımı testi $(0,5 \mathrm{~mm} / \mathrm{min})$ uygulandı. Data iki yönlü varyans analizi kullanılarak analiz edildi $(\alpha=0.05)$.

Bulgular: Farklı tip siman kullanımı restore edilmiş dişlerin kırıma dayanımını etkilemezken $(p=0.209), 10 \mathrm{~mm}$ derinlikte post yerleşimi $5 \mathrm{~mm}$ derinlikte yerleşime göre daha yüksek kııılma dayanımı göstermiştir $(p<0.001)$.

Sonuç: Çalışmanın limitasyonları dahilinde, hangi tip simanın kullanıldığına bakılmaksızın, post boşluğunun daha derin açılması post-kor destekli kron restorasyonlu dişlerin kırıma dayanımını artırmaktadır.

\section{ANAHTAR KELIMELER}

Baskı dayanımı, diş kırıkları, post ve kor tekniği

Çürük ve endodontik tedavinin bir parçası olan giriş kavitesi hazırlanması nedeniyle ciddi diş doku kaybı olan endodontik tedavi görmüş dişler, canlı dişlere göre kırımalara daha eğilimlidirler (Schwartz ve Robbins 2004). Pulpası çıkartılmış dişlerde vertikal kök kırımalarından kaçınmak amacıyla endodontik ve restoratif işlemlerde minimal preparasyon tavsiye edilse

\section{ABSTRACT \\ Effects of different cement usage and different post lengths to the fracture resistance of crown resorted teeth}

Background: The aim of this study is to evaluate the effect of post lengths and different cementation materials on the fracture resistance of teeth which restored with post-cores and crowns.

Methods: Forty mandibular premolars with similar dimensions were decoronated. After the root canal treatment, the teeth were embedded in acrylic blocks. Specimens were fistly divided into 2 groups. 10-mm- and 5-mm-long circular post spaces were prepared with using \#0.5 and \#2 coded manufacturer's drills, respectively. At the post (D.T. Light-Post) cementation stage, 10 specimens in each post group were cemented with a selfadhesive resin cement (Rely X). The other 10 specimens were cemented with self-etch cement (Clearfill Esthetic Cement) $(n=10)$. All specimens were restored with composite cores and prepared at a height of $6 \mathrm{~mm}$ (including $1 \mathrm{~mm}$ ferrule) and a convergence angle of approximately $5^{\circ}$ in total. Then, all teeth were restored with full metal crowns and cemented with a glass ionomer cement. After thermocycling, all specimens were subjected to fracture resistance testing $(0,5 \mathrm{~mm} / \mathrm{min})$. Data were analyzed using the two-way ANOVA test $(\alpha=0.05)$.

Results: Usage of different type of cement did not effect the fracture resistance of crown-restored $(p=0.209)$, while $10-\mathrm{mm}$ long post placement provided higher fracture resistance when compared to 5 -mm-long post placement $(p<.001)$.

Conclusion: Within the limitations of this study, deeply preparation of post place is enhanced fracture resistance of postcore and crown restored teeth whichever cement were used.

\section{KEYWORDS}

Compressive strength, post and core technique, tooth fractures

de, sıklıkla ilgili dişin restorasyonu için koronal yapıdan önemli derecede aşındırma gerekmektedir (Reeh ve ark. 1989). Bu amaçla restorasyonun kor kısmında yeterli retansiyon ve rezistansın sağlanması için post uygulamaları gerekmektedir (Robbins 1990). Elastiklik modülünün dentinle uyumlu olması ve adeziv rezinlerle dentine iyi bağlanma sergilediklerinden

\footnotetext{
* 22. Uluslarası Türk Prostodonti ve İmplantoloji Derneği Bilimsel Kongresinde (12-15 Kasım 2015) sunulmuştur.

1 Erciyes Üniversitesi Diş Hekimliği Fakültesi Protetik Diş Tedavisi Anabilim Dalı, Kayseri

2 Erciyes Üniversitesi Diş Hekimliği Fakültesi Endodonti Anabilim Dalı, Kayseri

3 Trakya Üniversitesi Diş Hekimliği Fakültesi Protetik Diş Tedavisi Anabilim Dalı, Edirne
} 
dolayı fiber postlar, post uygulamalarında tercih edilmektedir (Kilic ve ark. 2013). Bu özelliklerinin sonucu olarak, kök yapısı genelinde dengeli stres dağılımı elde edilmektedir (Kremeier ve ark. 2008; Kilic ve ark. 2013).

Bazı çalışmalar, stresi daha iyi dağıtığı ve daha fazla adeziv bağlanma alanı sağlayıp kök kırık riskini azalttığı iddiasıyla uzun fiber postların kullanımını tavsiye etmektedir (Asmussen ve ark. 2005; Boschian Pest ve ark. 2006). Bazı çalışmalarda ise, buna karşıt olarak, yerleştirilen postun boyunun artmasıyla endodontik tedavi görmüş dişin kırıma dayanımının artmadığ belirtilmektedir (Scotti ve ark. 2006). Bu nedenle fiber post uygulamasında postun ideal yerleştirilme boyunun belirlenmesine yönelik çalışmalara intiyaç vardır.

Fiber post simantasyonunda kullanılması tavsiye edilen simanlardan kendinden adezivli (self-adhesive) ve kendinden asitli (self-etch) kompozit simanlar öne çıkmaktadır. Kendinden asitli simanlar çoklu basamak işlemleri gerektirmektedir. Bu nedenle klinik uygulamaları kendinden adezivli simanlara göre daha zordur (Monticelli ve ark. 2008). Farklı tip adeziv simanla post simantasyonunun restore edilmiş dişlerin kırıma dayanımlarına etkilediğini gösteren çalışmalar olmakla birlikte (Naumann ve ark. 2006) yeni çalışmalara intiyaç vardır.

Termal döngü post sistemlerinin bağlantısı etkileyen önemli faktörlerden biridir (Mazzitelli ve ark. 2011). Ağız ortamını taklit eden termal döngü ile materyaller arası adeziv tabakayı etkileyebilecek, termal genleşme ve büzülmeye bağlı stresler oluşur (El Araby ve Talic 2007). Ayrıca önceki çalışmalarca termal döngü ile gerçekleşen siman genleşmesinin kök kanalı ile mekanik retansiyonu artırdığı bildirilmiştir (Mazzitelli ve ark. 2011).

Bu çalışmanın amacı, farklı boylarda yerleştirilen fiber postların endodontik tedavi görmüş dişlerin dayanıklı̆̆ı̆ı etkisini değerlendirmektir. Ayrıca, post simantasyonunda kullanılan iki farklı adeziv siman da dişlerin kırıma dayanımına etkisi değerlendirilmiştir. Bu çalışmada farklı boylarda farklı tip adeziv simanlarla simante edilen fiber postların dişlerin kırıma dayanımı üzerine etkisi yoktur sıfır hipotezi test edilmektedir.

\section{MATERYAL VE METOD:}

Periodontal sebeplerle çekilmiş benzer boyutlardaki alt çene birinci küçük azı dişleri $(21.3 \pm 0.7)$ ve serum fizyolojikte saklandı. Çalışmaya, bu dişlerden apeks gelişmesini tamamlamış tek köklü dişler dahil edildi, kanal tedavisi görmüş, çürüklü veya kırık/çatlak gözlenen dişler çalışmadan çıkartıldı. Bu kriterleri sağlayan 40 diş seçildi. Kök yüzeyi üzerindeki yumuşak dokular ve diş taşları nazikçe el küretleri ve kretuarlarla kök yüzeyinden uzaklaştıııdı.
Kök uzunluğunu standardize etmek için, dişler uzun aksa dik olacak şekilde apeksten $14 \mathrm{~mm}$ servikalden düşük hızlı elmas testere ile kesildi (Isomet, Buehler, Lake Bluff, IL, ABD). Çalışma boyu anatomik apeksten $1 \mathrm{~mm}$ kısa olacak şekilde belirlendi. Tüm kökler ProTaper Ni-Ti döner alet sistemiyle (Dentsply Maillefer, Ballaigues, İsviçre) ProTaper F3 ana apikal eğe olacak şekilde prepare edildi. Her bir enstrüman arasında $5 \mathrm{~mL}$ $\% 2,5$ 'lik $\mathrm{NaOCl}$ ile irrigasyon sağlandı. Preparasyonlar sonrasında 1 dakika boyunca $5 \mathrm{~mL} \% 17^{\prime}$ lik etilendiamintetraasetik asitle (EDTA) son irrigasyon yapıldı ve $10 \mathrm{ml}$ distile su ile kanal yüzeyleri yıkandı. Kök kanalları kağıt konlarla kurulandı. Güta-perka (Diadent Group International, Chongchong Buk Do, Kore) ve rezin esaslı pat (AH Plus, Dentsply DeTrey, Konstanz, Almanya) kullanılarak lateral kondensasyon tekniği ile kanallar dolduruldu ve kanal ağızları geçici dolgu materyali (CavitTM-G; 3M ESPEAG, Seefeld, Almanya) ile örtülenerek dişler 7 gün boyunca $37^{\circ} \mathrm{C}$ 'de \%100 nemli ortamda saklandı. Daha sonra, dişler $2 \mathrm{~cm}$ çapında ve $3 \mathrm{~cm}$ boyundaki plastik silindirler içine dökülen otopolimerize akrilik rezin (Elite SC Tray, Zhermack, Rovigo, İtalya) içerisinde mine-sement birleşiminden $2 \mathrm{~mm}$ apikal seviyeye kadar kalıplandı. Rezin polimerizasyonu sırasında dentin dehidratasyonundan kaçınmak için su ile soğutma sağlandı.

Hazırlanan örnekler, farklı post yerleştirme derinlikleri ve farklı yapıştırıcı siman kullanılarak (Resim 1) restore edilmek üzere, rastgele olarak dört gruba ayrıldı $(n=10)$. Grup 1: $10 \mathrm{~mm}$ post derinliği + kendinden asitli kompozit siman kullanımı, Grup 2: $10 \mathrm{~mm}$ post derinliği +kendinden adezivli rezin siman kullanımı, Grup 3: 5 $\mathrm{mm}$ post derinliği + kendinden asitli kompozit siman kullanımı, Grup 4: $5 \mathrm{~mm}$ post derinliği + kendinden adezivli rezin siman kullanımı. Grup 1 ve Grup 2'deki örneklerin güta-perkaları 3 numaralı Gates-Glidden frezleri (Mani Inc., Tochigi, Japonya) ile $10 \mathrm{~mm}$ 'lik post boşluğu elde edilinceye kadar boşaltıldı. Post sistemi üreticisinin talimatları doğrultusunda, sırasıyla preparasyon frezi (\#0.5, D.T. Light-Post; Bisco Inc., Schaumburg, IL, ABD) ve bitirme frezleri (\#2, D.T. LightPost; Bisco Inc.) ile kanal genişletilmesi su soğutması altında gerçekleştirildi. Kanal preparasyonu esnasında $\% 2,5^{\prime}$ lik $\mathrm{NaOCl}$ solüsyonu lubrikant etki elde etmek amacıyla kullanıldı. Frez hızı 8000 rpm olarak ayarlandı ve preparasyonlar bu gruplar için $10 \mathrm{~mm}$ 'de tamamlandı. Grup 3 ve Grup 4' deki örneklerde aynı işlemler çalışma boyu $5 \mathrm{~mm}$ olacak şekilde gerçekleştirildi.

Grup 2 ve Grup 4'teki örneklerde kendinden adezivli rezin siman (RelyX Unicem, 3M ESPE, St. Paul, MN, $A B D$ ) kullanıldı. Simantasyonda, otomatik karıştııcı ile karıştırılan siman post etrafına kaplanırken, lentülo ile kanal duvarlarına yayıldı ve postlar kanala hava boşluklarından kaçınmak için nazikçe yerleştirildi. Koronal alana taşan fazla siman pamuk fırça ile 
uzaklaştıııdı. Yerleştirilen postun oynamaması için devamlı parmak basıncı uygulandı. Bu şekilde 2 dakika boyunca her açıdan 40'ar saniye olmak üzere farklı açılardan ışıkla polimerizasyon gerçekleştirildi.

Grup 1 ve Grup 3' teki örneklerde kendinden asitli kompozit siman (Clearfil Esthetic Cement, Kuraray, Tokyo, Japonya) kullanıldı. Üretici talimatlarınca, fiber postlar 5 dakika KEcthant jeli ile asitlendi, sonrasında yıkandı ve hava ile nazikçe kurutuldu. Yüzey hazırlığını tamamlamak için fiber post yüzeylerine Clearfill seramik primer uygulandı ve hava ile kurutuldu. Eşit miktarlardaki ED Primer II A ve B sivıları karıştırılarak kanal dentin yüzeylerine 30 saniye boyunca tatbik edildi ve nazikçe kurulandı. Simantasyonda, otomatik karışııııcı ile karıştııılan siman post etrafına kaplanırken, lentilo ile kanal duvarlarına yayıldı ve postlar kanala hava boşluklarından kaçınmak için nazikçe yerleştirildi. Koronal alana taşan fazla siman pamuk firça ile uzaklaştırıldı. Yerleştirilen postun oynamaması için devamlı parmak basıncı uygulandı. Bu şekilde 2 dakika boyunca her açıdan 40'ar saniye olmak üzere farklı açlardan ışıkla polimerizasyon gerçekleştirildi.

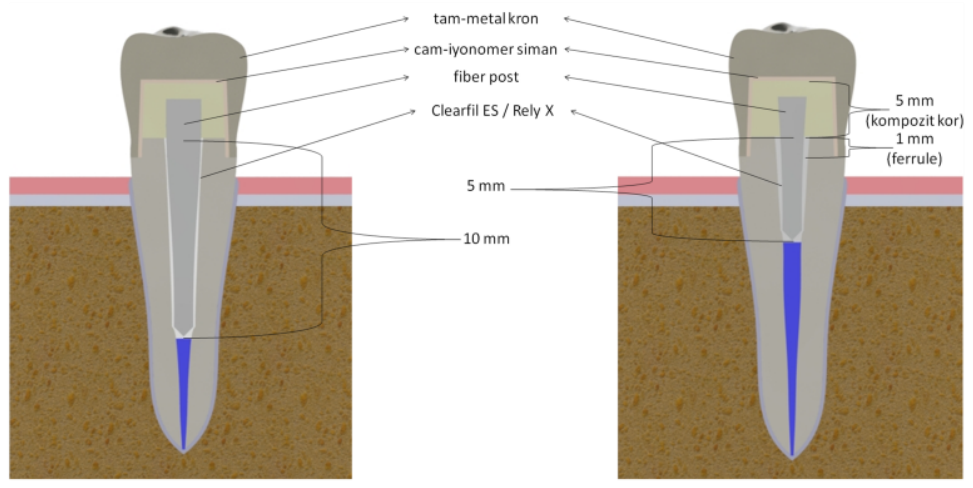

Resim 1.

Test edilen örneklerin restorasyon detayları

Kor içinde kalacak post yüzeylerine ve koronal diş yüzeylerine bağlayıcı ajan (Clearfil SE Bond, Kuraray, Japonya) uygulandı ve 20 saniye boyunca Işıkla polimerize edildi. Kompozit rezin kor, her tabakası $2 \mathrm{~mm}$ olacak şekilde, tabakalama tekniği ile yapıldı ve her tabaka 40 saniye boyunca ışıkla polimerize edildi. Tüm dişler $6 \mathrm{~mm}$ boyunda (1 $\mathrm{mm}$ 'si ferrule bileziği) ve yaklaşık $5^{\circ}$ lik konverjans açısıyla chamfer marjin dizaynı ile prepare edildi (Resim 1). Sonrasında her diş kendisine özgü üretilmiş Ni-Cr (Rubyalloy, Rubydent, İstanbul, Türkiye) döküm metal kron ile restore edildi. Kronlar cam iyonomer siman (Ketac-Cem, ESPE, Seefeld, Almanya) ile simante edildi ve sonrasında termal döngü öncesi $37^{\circ} \mathrm{C}$ 'de $\% 100$ nemli ortamda saklandı.

Kırılma testine geçmeden önce, örnekler 5000 termal döngüye (5-55 ${ }^{\circ} \mathrm{C}$; 30 sn daldırma süresi; 2 sn transfer süresi; Termalsiklus, Dentall Teknik, Konya, Türkiye) tabi tutuldu. Kırıma dayanımı testleri, üniversal test cihazı (Instron, Canton, MA, ABD) ile $0,5 \mathrm{~mm} /$ dak. hızında gerçekleştirildi. Testlerde $45^{\circ}$ lik oblik kuvvet fonksiyonel kuspa uygulanarak (Resim 2) kırımaya yol açan kuvvetler Newton (N) cinsinde kaydedildi.
Kırılmış dişler gözlenerek arzu edilen ve edilmeyen kırık tipleri olmak üzere kırılan dişin restore edilebilirliği göz önünde bulundurularak sınıflandırıldı.

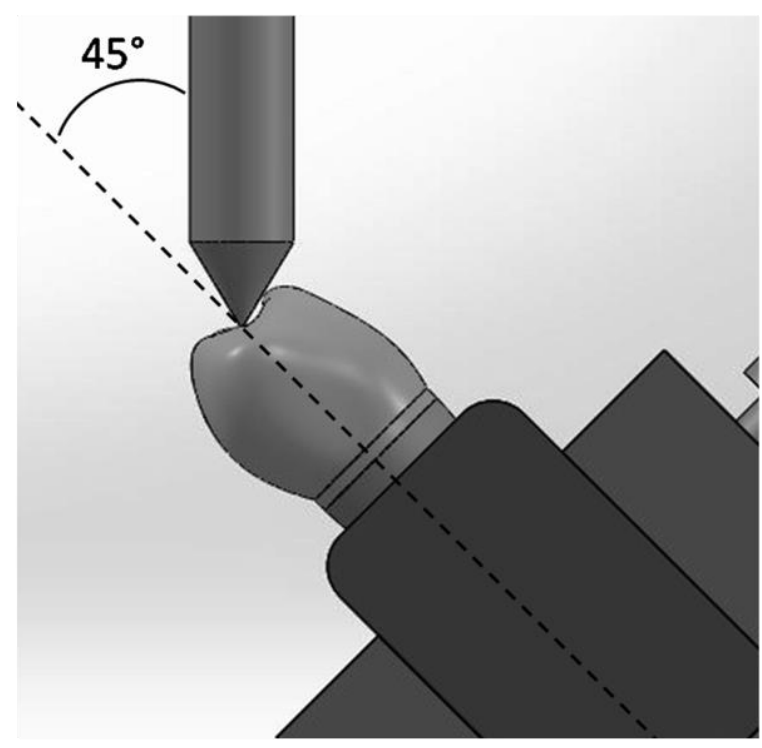

Resim 2.

Kırılma dayanımında uygulanan kuvvetin şematik görünümü

Elde edilen verilerin Kolmogorov-Smirnov testi ile normaliteleri değerlendirildi ve verilerin normal dağıldığı gözlemlendi. İki-yönlü varyans analizi (Two-way ANOVA) ile farklı boyutlarda fiber post yerleşiminin ve farklı siman kullanımının örneklerin kırıma dirençleri üzerine etkisi değerlendirildi. Ki-kare testi ile faktörlerin kırıma tiplerine olan etkisi değerlendirildi. İstatistiksel analizler \%95 güven aralığında SPSS 20.0 (IBM Corporation Software Group, NY, ABD) paket programı kullanılarak gerçekleştirildi.

\section{BULGULAR}

Çalışmada oluşturulan grupların ortalama kırıma dayanımı değerleri Tablo 1'de gösterilmiştir. İkiyönlü varyans analizi sonuçlarına göre (Tablo 2), $10 \mathrm{~mm}$ 'lik post yerleşimi $(216,01 \pm 53,9) 5 \mathrm{~mm}$ 'ye $(166,92 \pm 40,6)$ kıyasla anlamlı derecede yüksek kırıma dayanımı sergilerken $(p<0,05)($ Grafik 1$)$; kendinden adezivli rezin siman $(182,03 \pm 50,5)$ ve kendinden asitli kompozit siman $(201,94 \pm 55,5)$ kullanımı kırıma dayanımına istatistiksel olarak anlamlı derecede etki etmemektedir $(p>0,05)$. Ki-kare testi sonuçlarına göre farklı tip siman kullanımının veya farklı boyda post yerleştirmenin restore edilmiş dişlerin kırılma tiplerine etkisi gözlenmemiştir (p>.05) (Tablo 3). 
Tablo 1. Grupların kırılma dayanımı değerleri

\begin{tabular}{|lc|}
\hline & Ortalama \pm Standart Sapma (N) \\
\hline Grup 1 & $299,09 \pm 50,7$ \\
\hline Grup 2 & $204,23 \pm 56,5$ \\
\hline Grup 3 & $174,80 \pm 48,2$ \\
\hline Grup 4 & $159,82 \pm 33,3$ \\
\hline
\end{tabular}

Tablo 2. İki-yönlü varyans analizi sonuçları

\begin{tabular}{|lccccc|} 
Faktörler & $\begin{array}{c}\text { Kareler } \\
\text { Toplamı }\end{array}$ & df & $\begin{array}{c}\text { Kareler } \\
\text { Ortalaması }\end{array}$ & F & p \\
\hline Boy & 23070,4 & 1 & 23070,4 & 10,077 & 0,003 \\
\hline Siman & 3758,44 & 1 & 3758,44 & 1,642 & 0,209 \\
\hline Boy $\times$ Siman & 231,08 & 1 & 231,08 & 0,101 & 0,753 \\
\hline Hata & 77841,43 & 34 & 2289,45 & & \\
\hline Total & 1497704,91 & 38 & & & \\
\hline
\end{tabular}

Tablo 3. İki-yönlü varyans analizi sonuçları

\begin{tabular}{|llcccc|} 
& \multicolumn{4}{c}{ FACTORS } \\
\cline { 2 - 6 } & \multicolumn{3}{c}{ Kost Uzunluğu } & \multicolumn{2}{c|}{ Siman Tipi } \\
\cline { 2 - 6 } & $\mathbf{5 ~ m m}$ & $\mathbf{1 0} \mathbf{~ m m}$ & Rely X & Clearfil \\
\hline Arzu Edilen & 10 & 7 & 10 & 12 \\
\hline Arzu Edilmeyen & 10 & 13 & 10 & 8 \\
\hline Ki-Kare p Değerleri & & 0,337 & \multicolumn{2}{c}{0,525} \\
\hline
\end{tabular}

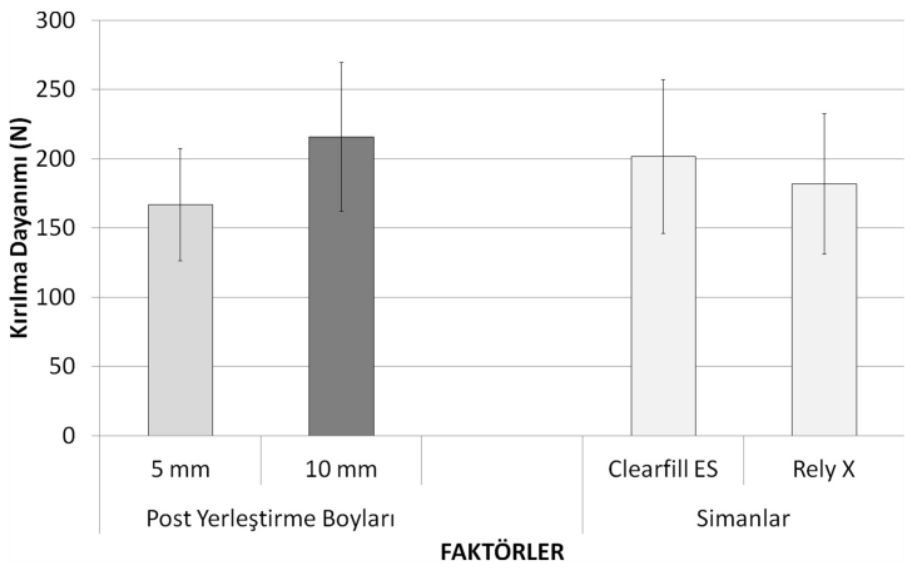

Grafik 1.

Test edilen faktörlerin ortamala-standart sapma grafiği

\section{TARTIŞMA}

Elde edilen sonuçlar ışığında, daha uzun post kullanımı kırıma dayanımını artıııken, farklı tip adeziv siman kullanımı kırıma dayanımına etki etmemiştir ve çalışmanın hipotezi parçalı olarak kabul edilmiştir. Literatürde fiber postların kök kanalı içerisine yerleştirilme boyutuyla ilgili kesin bir kanı hala oluşmamıştır. Fernandes ve Dessai (Fernandes ve Dessai 2001), ancak daha rijit bir yapı ve daha az kök eğilmesi sağladığından dolayı uzun boylu fiber post kullanımının daha yüksek kırılma dayanımı sergilediğini rapor etmişlerdir. Adanır ve Belli (Adanir ve Belli 2008), klinik başarısızlıktan kaçınmak için kısa boylu post yerleşiminden kaçınılması gerektiğini belirtmişlerdir. Bunlara zıt olarak, Cechin ve ark. (Cecchin ve ark. 2010) $8 \mathrm{~mm}$ ve $12 \mathrm{~mm}$ boylarında yerleştirdikleri postlar ile benzer kırıma dayanımları elde etmişler ve daha fazla preparasyon gerektiren uzun boylu post yerleşimine şüphe ile yaklaşmışlardır.

Bu çelişkili bulguların nedeni, farklı çalışmalarda farklı deneysel protokollerin tercih edilmesi olabilir. Bu çalışmada, klinik koşulların deney ortamına daha iyi yansıtılabilmesi için kırılma dayanımı testleri, tam metal kronlarla restore edilen ve termal döngüye giren diş örnekleri üzerinde gerçekleştirilmiştir. Yine klinik ortamının daha iyi yansitılabilmesi amaciyla, kron preparasyonu sırasında $1 \mathrm{~mm}$ ferrule bileziği de oluşturulmuştur. Endodontik tedavi görmüş dişlerde yapılan ferrule dizaynının, dişlerin kırılma dayanımına pozitif etkisinin olduğu daha önceki çalışmalarda rapor edilmiştir (Isidor ve ark. 1999; Tan ve ark. 2005). Bu çalışmanın sonuçlarına göre, fiber postun kök kanalına $10 \mathrm{~mm}$ boyunda yerleştirilmesi, kullanımış olan adeziv simanın tipine bağlı olmaksızın, $5 \mathrm{~mm}$ boyunda yerleştirilmesinden daha fazla kırılma direnci ortaya koymuştur. Bunun nedeni, uzun yerleştirilen postlarda daha fazla bağlanma yüzeyi sebebiyle streslerin daha fazla dentin yapısına dağııması olabilir.

Kendinden adeziv simanların kendinden asitli simanlara benzer dentin bağlanım dayanımları gösterdikleri önceki çalışmalarda bildirilmiştir (De Munck ve ark. 2004; Naumann ve ark. 2005; Zicari ve ark. 2008). Kendinden adeziv simanlar kendinden asitli simanlardan farklı olarak, ilave adeziv uygulaması gerektirmezler. Siman materyali içerisinde bulunan asidik monomerler ile ıslanma ve dentine bağlantı arttırılır (Van Landuyt ve ark. 2007). Bu çalışmanın bulgularına 
göre, iki yapıştırıcı siman arasında restore edilmiş dişin kırıma dayanımlarına etkisi açısından farklılık gözlenmemiştir. Bu sonuç önceki çalışmalarla da uyumludur (Zicari ve ark. 2008; Zicari ve ark. 2012).

Önceki bir çalışma göz önünde bulundurularak kırıma tipleri arzu edilen ve edilmeyen olarak sınıflandırımıştır (Kumagae ve ark. 2012). Post desimantasyonu veya servikal üçlüde lokalize kök kırıkları restore edilebilecek kırımalar olarak öngörülmüş olup, arzu edilen kırıklar olarak sınıflandırımıştır. Servikal üçlüyü aşan kök kırıkları ise restore edilemeyeceği öngörülüp arzu edilmeyen kırıklar olarak sınıflandırımıştır. Post uzunluğunun kök orta üçlüye uzanması ile stres konsantrasyonunun apikal bölgede yoğunlaştığı rapor edilmiştir (Hunter ve ark. 1989). Ancak, çalışmamızın sonuçlarına göre kırılma tipleri ne kullanılan siman farklıığından ne de yerleştirilen postun boyundan etkilenmiştir. Fonksiyonel kuspa uygulanan oblik kuvvetin ve post ucu lokalizasyonunun daha az arzu edilmeyen kırık beklenebilecek $5 \mathrm{~mm}$ post yerleşiminde kırımaların kök orta üçlüsüne uzanması nedeniyle farklılık oluşturmadığı düşünülmektedir. $5 \mathrm{~mm}$ post yerleşimini simüle eden sonlu elemanları analizi çalışmaları bu düşünceyi desteklemektedir. Bu çalışmalara göre oblik kuvvet uygulanması ile stres konsantrasyonunun kök orta üçlüde oluştuğu bildirilmiştir (Chuang ve ark. 2010).

Bitter ve ark. (Bitter ve ark. 2006) ve Egilmez ve ark. (Egilmez ve ark. 2013) 5000 termal döngünün uygulanması ile kendinden adezivli ve kendinden asitli simanların bağlantı dayanımlarında artış gözlemlemişlerdir. Çalışmamızda klinik koşulları standardize etmek adına aynı sayıda termal döngü uygulanmış ve post-kök kanalı bağlantısından emin olunarak kırıma dayanımı testi gerçekleştirilmiştir. Diğer taraftan bu çalışmanın en önemli limitasyonu olarak, kırıma testi esnasında statik bir kuvvetin uygulanmış olması gösterilebilir. İlerleyen çalışmalarla çiğneme simülatörü altında dişlere dinamik kuvvetlerin uygulanarak gerçekleştirilecek yorulma ile daha güvenilebilir sonuçlar elde edilebilir. Ayrıca uzun dönem klinik takip çalışmaları ile mevcut sonuçların desteklenmesi gereklidir.

\section{ÖNERILER}

Çalışmamızda termal döngü ile yorma, ferrule oluşumu, ideal diş preparasyon dizaynı gibi etkenler ile klinik simülasyon yapılmaya çalışılmıştır. $\mathrm{Bu}$ in vitro çalışmanın limitasyonları dahilinde, farklı tip adeziv siman kullanılması post-kor destekli metal kron restorasyonlu dişlerin kırılma dayanımını etkilemezken, post boşluğunun daha derin açılması kııııma dayanımını arttırmaktadır. 


\section{KAYNAKLAR}

Adanir N, Belli S, 2008. Evaluation of different post lengths' effect on fracture resistance of a glass fiber post system. Eur J Dent, 2(1), 23-28.

Asmussen E, Peutzfeldt A, Sahafi A, 2005. Finite element analysis of stresses in endodontically treated, dowel-restored teeth. J Prosthet Dent, 94(4), 321-329.

Bitter K, Meyer-Lueckel H, Priehn K, Kanjuparambil J P, Neumann K, Kielbassa A M, 2006. Effects of luting agent and thermal cycling on bond strengths to root canal dentine. Int Endod J, 39(10), 809-818.

Boschian Pest L, Guidotti S, Pietrabissa R, Gagliani $M, 2006$. Stress distribution in a post-restored tooth using the three-dimensional finite element method. J Oral Rehabil, 33(9), 690-697.

Cecchin D, Farina A P, Guerreiro C A, Carlini-Junior $B, 2010$. Fracture resistance of roots prosthetically restored with intra-radicular posts of different lengths. J Oral Rehabil, 37(2), 116-122.

Chuang S F, Yaman P, Herrero A, Dennison J B, Chang $\mathrm{C} \mathrm{H}, 2010$. Influence of post material and length on endodontically treated incisors: an in vitro and finite element study. J Prosthet Dent, 104(6), 379-388.

De Munck J, Vargas M, Van Landuyt K, Hikita K, Lambrechts P, Van Meerbeek B, 2004. Bonding of an auto-adhesive luting material to enamel and dentin. Dent Mater, 20(10), 963-971.

Egilmez F, Ergun G, Cekic-Nagas I, Vallittu P K, Lassila L V, 2013. Influence of cement thickness on the bond strength of tooth-colored posts to root dentin after thermal cycling. Acta Odontol Scand, 2013 71(1), 175-182.

El Araby A M, Talic Y T, 2007. The effect of thermal cycling on the adhesion of self-etching adhesives on dental enamel and dentin. J Contemp Dent Pract, 8(2), 17-24.

Fernandes A S, Dessai G S, 2001. Factors affecting the fracture resistance of post-core reconstructed teeth: a review. Int J Prosthodont, 14(4), 355-363.

Hunter A J, Feiglin B, Williams J F, 1989. Effects of post placement on endodontically treated teeth. $J$ Prosthet Dent, 62(2), 166-172.

Isidor F, Brondum K, Ravnholt G, 1999. The influence of post length and crown ferrule length on the resistance to cyclic loading of bovine teeth with prefabricated titanium posts. Int J Prosthodont, 12(1), 78-82.
Kilic K, Er O, Kilinc H I, Aslan T, Bendes E, Sekerci A E, Aslantas V, 2013. Infrared thermographic comparison of temperature increases on the root surface during dowel space preparations using circular versus oval fiber dowel systems. J Prosthodont, 22(3), 203-207.

Kremeier K, Fasen L, Klaiber B, Hofmann N, 2008. Influence of endodontic post type (glass fiber, quartz fiber or gold) and luting material on pushout bond strength to dentin in vitro. Dent Mater, 24(5), 660-666.

Kumagae N, Komada W, Fukui Y, Okada D, Takahashi H, Yoshida K, Miura H, 2012. Influence of the flexural modulus of prefabricated and experimental posts on the fracture strength and failure mode of composite resin cores. Dent Mater J, 31(1), 113-119.

Mazzitelli C, Monticelli F, Toledano M, Ferrari M, Osorio R, 2012. Effect of thermal cycling on the bond strength of self-adhesive cements to fiber posts. Clin Oral Investig, 2012 16(3), 909-915.

Monticelli F, Ferrari M, Toledano M, 2008. Cement system and surface treatment selection for fiber post luting. Med Oral Patol Oral Cir Bucal, 13(3), E214-221.

Naumann M, Blankenstein F, Dietrich T, 2005. Survival of glass fibre reinforced composite post restorations after 2 years-an observational clinical study. J Dent, 33(4), 305-312.

Naumann M, Preuss A, Frankenberger R, 2006. Load capability of excessively flared teeth restored with fiber-reinforced composite posts and allceramic crowns. Oper Dent, 31(6), 699-704.

Reeh E S, Messer H H, Douglas W H, 1989. Reduction in tooth stiffness as a result of endodontic and restorative procedures. J Endod, 5(11), 512-516.

Robbins J W, 1990. Guidelines for the restoration of endodontically treated teeth. J Am Dent Assoc, 120(5), 558-562.

Schwartz R S, Robbins J W, 2004. Post placement and restoration of endodontically treated teeth: a literature review. J Endod, 30(5), 289-301.

Scotti R, Valandro L F, Galhano G A, Baldissara P, Bottino M A, 2006. Effect of post length on the fatigue resistance of bovine teeth restored with bonded fiber posts: a pilot study. Int $\mathrm{J}$ Prosthodont, 19(5), 504-506. 
Tan P L, Aquilino S A, Gratton D G, Stanford C M, Tan S C, Johnson W T, Dawson D, 2005. In vitro fracture resistance of endodontically treated central incisors with varying ferrule heights and configurations. J Prosthet Dent, 93(4), 331-336.

Van Landuyt K L, Snauwaert J, De Munck J, Peumans M, Yoshida Y, Poitevin A, Coutinho E, Suzuki K, Lambrechts P, Van Meerbeek B, 2007. Systematic review of the chemical composition of contemporary dental adhesives. Biomaterials, 28(26), 3757-3785.

Zicari F, Couthino E, De Munck J, Poitevin A, Scotti R, Naert I, Van Meerbeek B, 2008. Bonding effectiveness and sealing ability of fiber-post bonding. Dent Mater, 24(7), 967-977.

Zicari F, Van Meerbeek B, Scotti R, Naert I, 2012. Effect of fibre post length and adhesive strategy on fracture resistance of endodontically treated teeth after fatigue loading. J Dent, 40(4), 312-321.

\section{Yazışma Adresi:}

Dr.Halil ibrahim KILINÇ

Erciyes Üniversitesi

Diş Hekimliği Fakültesi Protetik Diş Tedavisi AD

Kayseri, Türkiye

Tel : +90 3522076666 - 29075 - 29085

Faks: +90352354 4380657

E-mail: hikilinc@erciyes.edu.tr 